\title{
Sera from chronic chagasic patients depress cardiac electrogenesis and conduction
}

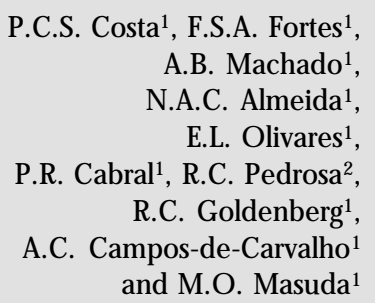

\author{
${ }^{1}$ Instituto de Biofísica Carlos Chagas Filho and \\ ${ }^{2}$ Hospital U niversitário Clementino Fraga Filho, \\ Universidade Federal do Rio de Janeiro, Rio de Janeiro, RJ, Brasil
}

\section{Correspondence \\ M.O. Masuda \\ Instituto de Biofísica \\ Carlos Chagas Filho, UFR \\ CCS, Bloco G, llha do Fundão \\ 21949-900 Rio de Janeiro, RJ \\ Brasil \\ Fax: + 55-21-280-8193 \\ E-mail: mmasuda@biof.ufrj.br \\ Presented at the Meeting "Gap Junctions in the Nervous and Cardiovascular Systems: Clinical Implications", Rio de Janeiro, RJ, Brazil, June 6-11, 1998.}

Research supported by CNPq, CAPES-MEC, FAPERJ, CEPG-UFRJ, $M C T-P R O N E X$ and FUJB.

Received January 19, 2000 Accepted February 3, 2000

\section{Abstract}

We report results obtained with sera from 58 chronic chagasic patients that were evaluated for effects on heart rate and atrioventricular (AV) conduction in isolated rabbit hearts and screened for the presence of muscarinic and beta-adrenergic activity. We show that sera from 26 patients decreased heart rate, while 10 increased it and 22 had no effect. Additionally, sera from 20 of the 58 patients blocked AV conduction. Muscarinic activation seems to be involved in both effects, but is not the only mechanism, since atropine did not antagonize the decrease in heart rate in $23 \%$ of sera or AV block in $40 \%$. Sera from patients with complex arrhythmias were significantly more effective in depressing both heart rate and AV conduction. Sera that induce increases in heart rate seem to operate exclusively through beta-adrenergic activation. Two of these sera, evaluated with respect to intercellular communication in primary cultures of embryonic cardiomyocytes were able to block gap junction conductance evaluated by a dye injection technique after 24-h exposure. The mechanisms underlying this uncoupling effect are currently being investigated.

\section{Introduction}

Chagas' disease results from a protozoan infection by Trypanosoma cruzi (1). The disease has both acute and chronic phases. During the chronic phase, live parasites are very rarely observed in blood or in the affected organs, leading to the view that autoimmune mechanisms may be responsible for the pathogenesis during the chronic stage. For as yet unexplained reasons the heart and gastrointestinal system are targets of the parasite, and chronic chagasic cardiopathy is char-

\section{Key words}

- Chagas' disease

- Antibodies

- Muscarinic activation

- Beta-adrenergic activation

- Gap junction

- Mammalian heart acterized by bradycardia, conduction disturbances, heart failure, thromboembolism and sudden death.

In a previous study on 10 patients, we have shown that sera from chronic chagasic (CCh) patients with complex arrhythmias decrease heart rate and induce atrioventricular (AV) conduction block (AVB). In contrast, sera from $\mathrm{CCh}$ patients without complex cardiac arrhythmias had no significant effect on these parameters (2). We further demonstrated that the depressing effects of the sera on cardiac electrogenesis were me- 
diated by the activation of muscarinic receptors by their IgG fraction $(2,3)$. We now report results obtained from experiments with sera from $58 \mathrm{CCh}$ patients that were screened for the presence of muscarinic activity, as well as beta-adrenergic activity as previously reported for other preparations by Borda and collaborators $(4,5)$. We evaluated the effects of sera on heart rate and AV conduction in isolated rabbit hearts and characterized the mechanisms underlying the observed effects by perfusing the same sera in the presence of atropine or propranolol.

We also report on preliminary experiments where we tested the effects of two of these sera, displaying beta-adrenergic-like effects, on intercellular communication in primary cultures of murine embryo cardiac myocytes.

\section{Material and Methods}

\section{ECG recordings in isolated rabbit hearts}

To evaluate the effect of serum on cardiac electrogenesis, isolated rabbit hearts were perfused by the Langendorff method as described by Farias de Oliveira et al. (2). The experimental protocol consisted of control recordings for 20-30 $\mathrm{min}$ in Tyrode solution (or in Tyrode containing atropine or propranolol, $1 \mu \mathrm{M}$ ), a 30-min perfusion with the previous solution containing serum from the chagasic patients diluted 1:100 (v/v) and a final perfusion in the control solution. The ECG was continuously monitored on an oscilloscope (561 Tektronix, Inc., Beaverton, OR, USA) and recorded on a chart recorder (2200, Gould Inc., Cleveland, OH, USA) and on a video recorder (Hi Fi Video Cassette Recorder, Sansui, Japan) using a Neuro Corder instrument (Neuro Data Instr. Corp., New York, NY, USA). Experiments were carried out only if no significant changes in the ECG parameters were observed for the 20-30-min period of the control recordings. The ECG analysis included $\mathrm{P}$ wave fre- quency, presence of AVB and other arrhythmias.

\section{Cultures of mouse embryo cardiac myocytes}

Cultures of cardiac myocytes were obtained as previously described (6). Briefly, hearts from 18-day-old in utero albino mice were aseptically removed, the atria were trimmed away and the ventricles minced into small fragments. These fragments were washed free of blood cells and incubated three to four times for $10 \mathrm{~min}$ with $\mathrm{Ca}^{2+}$ - and $\mathrm{Mg}^{2+}$-free salt solution containing $0.05 \%$ trypsin (Difco, Detroit, MI, USA) and $0.01 \%$ collagenase (Worthington, Type II) at $37^{\circ} \mathrm{C}$. Enzyme activity was interrupted with fetal calf serum (FCS). The suspension was centrifuged at low speed and the cell pellet resuspended in Dulbecco's Modified Eagle Medium (Sigma Chemical Co., St. Louis, MO, USA) with $15 \%$ horse serum, $5 \%$ FCS, $2 \%$ chick embryo extract, $1 \mathrm{mM}$ glutamine, $1000 \mathrm{U} / \mathrm{ml}$ penicillin and $50 \mu \mathrm{g} / \mathrm{ml}$ streptomycin. The cell suspension was then preplated in gelatin-coated culture flasks and incubated for $90 \mathrm{~min}$ at $37^{\circ} \mathrm{C}$ in a $5 \% \mathrm{CO}_{2}$ atmosphere. After this incubation the supernatant containing non-attached cells was removed and these cells were re-plated onto gelatin-coated coverslips placed in 24-well plates at approximately $5 \times 10^{5}$ cells $/ \mathrm{ml}$. Medium was replaced the following day. After $24 \mathrm{~h}$, fresh medium containing serum from $\mathrm{CCh}$ patients or from normal blood donors was added at 1:10 (v/v) dilution. Dye injection experiments were performed in these cultures $15 \mathrm{~min}$, and 4 and $24 \mathrm{~h}$ after this maneuver.

\section{Dye coupling}

Dye coupling was assayed by intracellular injection of Lucifer yellow into individual cells in culture. High resistance microelectrodes (30-50 M $\Omega$ if filled with $3 \mathrm{M}$ $\mathrm{KCl})$ were filled with a $5 \%$ solution of the 
dye in $150 \mathrm{mM} \mathrm{LiCl}$. Dye was injected into the cell cytoplasm after impalement by small $(10 \mathrm{mV})$ hyperpolarizing pulses. When the injected cell was distinctly bright, injection was stopped, the microelectrode withdrawn from the cell and dye spread to neighboring cells was scored and photographed (Kodak TMAX 400 film for $30 \mathrm{~s}) 1 \mathrm{~min}$ later. Fluorescence images were obtained using a Nikon Diaphot inverted microscope equipped with Xenon arc illumination and the appropriate filter set, as previously described (7).

\section{Patient follow-up and selection procedures}

Sera were obtained from chronic chagasic cardiopathic patients followed for several years at the Cardiomyopathy Research Clinic of Hospital Universitário Clementino Fraga Filho, UFRJ, Rio de Janeiro, Brazil. Sera from 58 patients with different clinical characteristics were assayed: 13 were classified as group I (10, IA and 3, IB), 28 as group II and 17 as group III according to the Los Andes classification $(8,9)$. According to the Lown criteria (10), 20 belonged to group 1 (16, 1A and 4,1B), 3 to group 2, 2 to group 3 , and 33 to group $4(15,4 \mathrm{~A}$ and $18,4 \mathrm{~B})$. Patients with concomitant arterial hyperten- sion, chronic obstructive pulmonary disease, cardiomyopathy of any etiology other than Chagas' disease, valvular heart disease, congenital cardiomyopathy, obstructive coronary disease, thyroid dysfunction, excessive alcohol consumption, known immunologic dysfunctions or systemic diseases were excluded from the study. Patients who participated in this study gave written informed consent. WHO and Helsinki Treaty regulations (1963), reviewed in Venice (1983), were followed and the study was approved by the Hospital Ethics Committee.

\section{Results and Discussion}

Of the $58 \mathrm{CCh}$ patients' sera tested for effects on cardiac electrogenesis, $26(45 \%)$ decreased and $10(17 \%)$ increased heart rate while $22(38 \%)$ did not change it. Sinus rates were considered to be significantly altered by serum perfusion when the decreases were larger than $10 \%$ (considering that a small, spontaneous, and gradual decrease in heart rate is observed in the isolated hearts) and the increases were larger than 5\%. Figure 1 summarizes the clinical characterization of each of the 58 patients whose sera were assayed, as well as the effects of perfusion

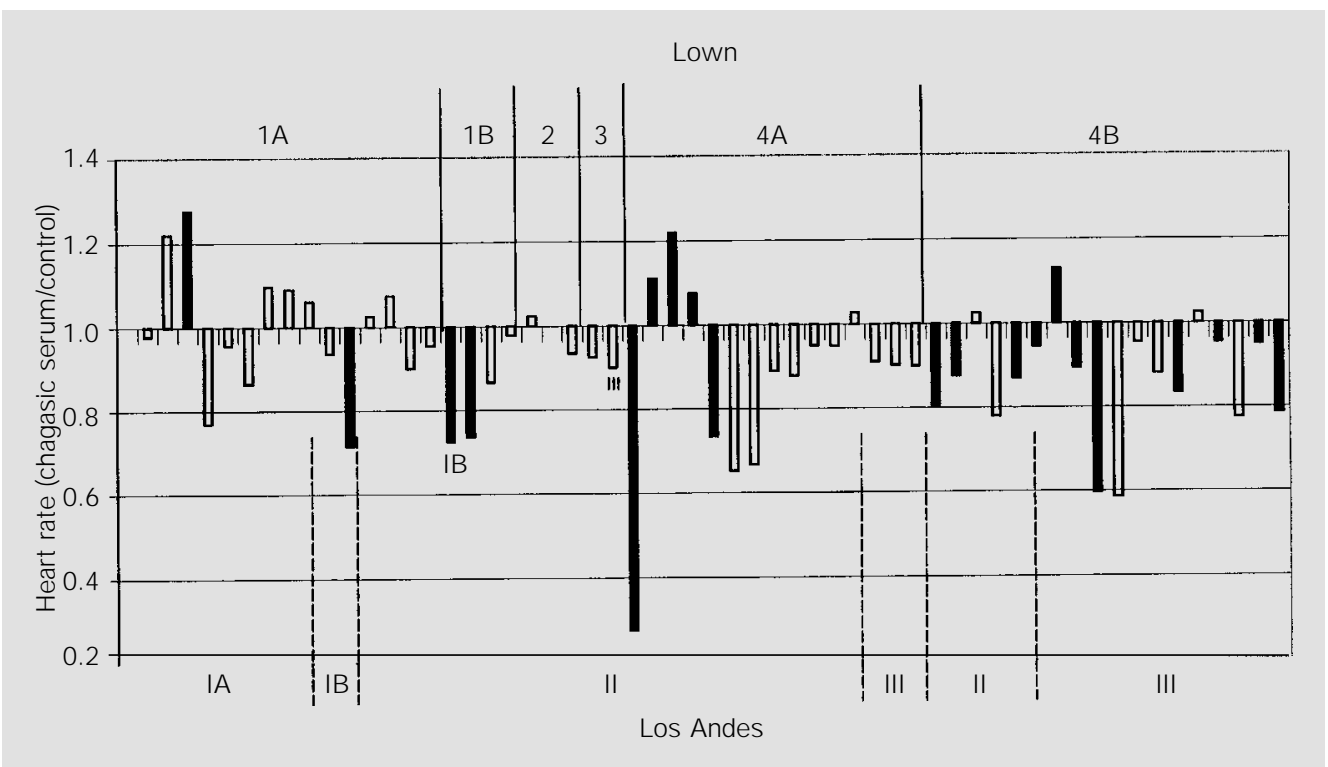

Figure 1 - Classification of chronic chagasic patients and effects of their sera on heart rate and atrioventricular conduction in isolated rabbit hearts. The results were listed according to the Lown classification of the patients as indicated at the top of the figure. Heart rate ratios higher than 1 indicate an increase in heart rate and ratios lower than 1 indicate a decrease in heart rate in the presence of serum. Black bars indicate induction of atrioventricular conduction block by serum. Patient classification according to the Los Andes criteria is shown at the bottom of the figure. All sera were tested diluted in Tyrode saline at 1:100 (v/v). 
Figure 2 - Effect of patient serum on isolated rabbit hearts. ECG recordings for each pair were obtained from the same heart in this and subsequent figures. The upper traces in each pair (control) represent ECG recorded during Tyrode perfusion. Lower traces (serum) were obtained in the presence of serum diluted 1:100 (v/v) in Tyrode solution. Sera from chronic chagasic patients can induce tachycardia (A) or bradycardia (B). Senum from a normal patient had no effect on cardiac electrogenesis (C). Horizontal bar $=1 \mathrm{~s}$.
Figure 3 - Muscarinic and betaadrenergic-like effects of sera from chronic chagasic patients. A, Control and washout traces represent ECG recorded during Tyrode perfusion, and the middle trace, labeled serum, was obtained in the presence of a serum that induced a decrease in sinus rate. $\mathrm{B}$, Control and washout, obtained in the presence of $1 \mu \mathrm{M}$ atropine; S/Atr, obtained with the same serum as used in A, now in the presence of $1 \mu \mathrm{M}$ atropine. In this case the serum did not induce bradycardia. C, Control and washout, perfusion with Tyrode; senum, in the presence of a serum inducing an increase in heart rate. $\mathrm{D}$, Control and washout in the presence of $1 \mu \mathrm{M}$ propranolol; S/Prop, in the presence of propranolol, the same serum as used in $\mathrm{C}$ did not induce tachycardia. Horizontal bar indicates $1 \mathrm{~s}$.

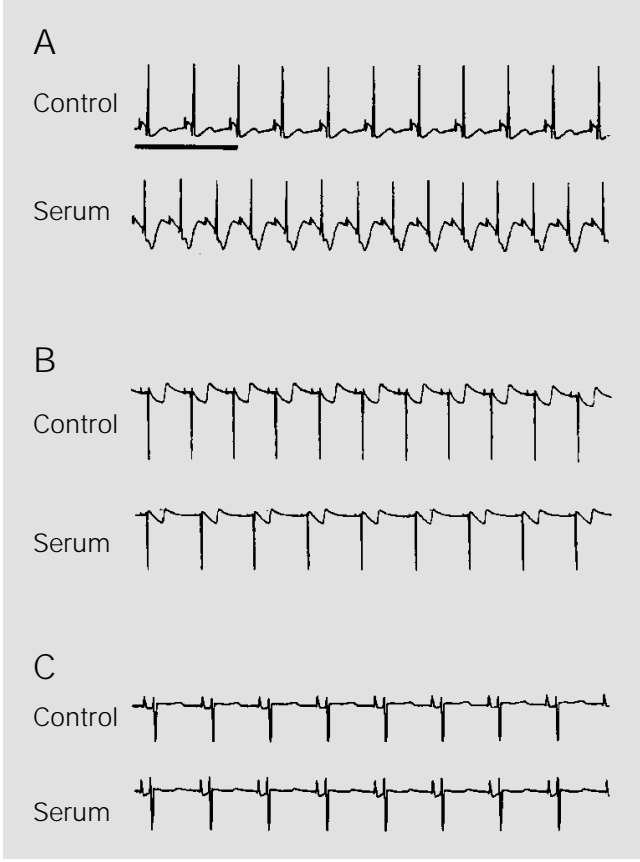

with these sera on heart rate and AV conduction in isolated rabbit hearts. Figure 2 shows results of typical experiments displaying increased (Figure 2A) and decreased (Figure 2B) heart rate in isolated rabbit hearts perfused with chagasic patients' sera as compared to the lack of effect during perfusion with serum from a normal blood donor (Figure $2 \mathrm{C}$ ).

These results show that the main effect of $\mathrm{CCh}$ patients' sera on cardiac activity is depression of electrogenesis, as previously reported by us (2), in contrast to the findings by Borda and collaborators $(4,5)$ who reported a primarily positive chronotropic and inotropic action of sera from $\mathrm{CCh}$ patients. More recently, other investigators have also reported results consistent with our observations (11) that only sera from a small fraction of the patients had antibodies recognizing beta-adrenergic receptors. One possible explanation for this discrepancy is related to differences in the experimental models used - primary cultures of rat embryo myocytes for chronotropic effects, and of rat atrium for inotropic effects, in the study by Borda et al. $(4,5)$ - compared to adult isolated rabbit heart used in our studies. Another is related to differences in the clinical stages of the patients: in our study, the patients had distinct clinical, hemodynamic and electrocardiographic disturbances, as can be seen from the wide distribution of the patients in both the Los Andes and Lown classifications (Figure 1), while Borda's group usually worked with sera from asymptomatic patients. We also cannot rule out differences related to the infective parasite strain, which are known to result in distinct clinical manifestations of the disease.

Among the 26 patient sera that decreased heart rate, $20(77 \%)$ had their effects blocked by atropine $(1 \mu \mathrm{M})$ while the remaining 7 continued to decrease heart rate in the presence of this muscarinic receptor antagonist, suggesting an interaction of these sera with non-muscarinic receptors. Figure 3A shows 
the result of one experiment in which atropine successfully antagonized the depressing effect of the serum on heart rate. All 10 sera inducing an increase in heart rate had their effects blocked by propranolol $(1 \mu \mathrm{M})$, as shown in Figure $3 \mathrm{~B}$, thus suggesting a beta-adrenergic activation. Our data indicate that sera from some $\mathrm{CCh}$ patients depress cardiac electrogenesis via a non-cholinergic pathway, while most others act through the already reported muscarinic activation.

Analysis of the experiments with sera derived from the 58 patients allowed us to confirm that the depressing effect of these sera is related to the severity of the cardiopathy and to the presence of complex cardiac arrhythmias in these patients. Figure 1 shows that most of the sera depressing heart rate were from $\mathrm{CCh}$ patients with complex arrhythmias $(\mathrm{CCh}+$, which includes groups 3 and 4 according to the Lown classification). Sera from this group significantly decreased heart rate (from $125 \pm 4 \mathrm{bpm}$ (means \pm SEM) during saline perfusion to $108 \pm 4$ in the presence of serum and $113 \pm 4$ upon washout; $\mathrm{N}=35$ ). In contrast, sera from patients without complex arrhythmias (CCh-, groups 1 and 2 of the Lown classification) did not significantly alter heart rate $(124 \pm 3 \mathrm{bpm}$ in saline compared to $119 \pm 5$ in the presence of sera and $119 \pm 4$ upon washout; $N=23$ ). The effects of control and patient sera were compared by ANOVA, followed by the StudentNewman-Keuls test.

Figure 4 shows recordings of an experiment performed with serum from a $\mathrm{CCh}$ patient that induced second degree AVB. Figure 1 shows that while sera from 16 of 35 (46\%) $\mathrm{CCh}+$ patients induced AVB, only 4 of $23(17 \%)$ sera from CCh- patients had this blocking effect. The Fisher exact test applied to these results confirmed the previous observation that sera from $\mathrm{CCh}$ patients with complex arrhythmias are significantly more effective in inducing AV conduction disturbances $(\mathrm{P}=0.047)$. No correlation between depression of heart rate and induction of AVB by individual sera could be established.

The ability to induce AVB was prevented by atropine $(1 \mu \mathrm{M})$ in 1 of 4 sera $(25 \%)$ in the CCh- group and in 11 of $16(70 \%)$ in the $\mathrm{CCh}+$ patients. The depressing effect on heart rate, on the other hand, could be reversed by atropine in 3 of 7 (43\%) CCh- and 16 of 19 (84\%) $\mathrm{CCh}+$ patients' sera. These results indicate a tendency for sera from $\mathrm{CCh}+$ patients to act preferentially via muscarinic activation while in sera from $\mathrm{CCh}$ - patients a non-muscarinic mechanism seems to predominate.

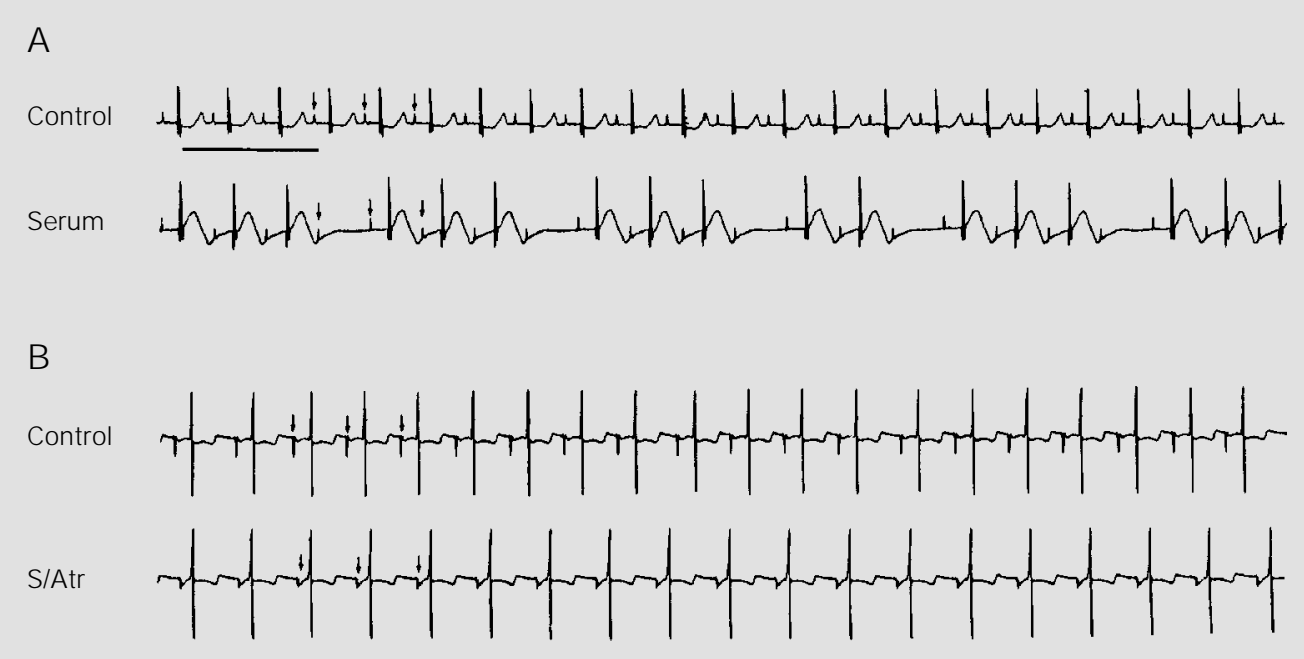

Figure 4 - Atrioventricular conduction block (AVB) induced by serum from a chronic chagasic patient in the isolated rabbit heart. The arrows point to $P$ waves. A, Control: during Tyrode perfusion; serum: ECG recording obtained in the presence of serum diluted 1:100 in Tyrode solution. Note the occurrence of AVB, characterized by several non-conducting $P$ waves (not followed by the QRS complex). B, Control: recording obtained during atropine $(1 \mu \mathrm{M})$ perfusion. $\mathrm{S} /$ Atr: ECG recording obtained during perfusion of the same serum used in $A$, now in the presence of $1 \mu \mathrm{M}$ atropine. Horizontal bar indicates $1 \mathrm{~s}$. 

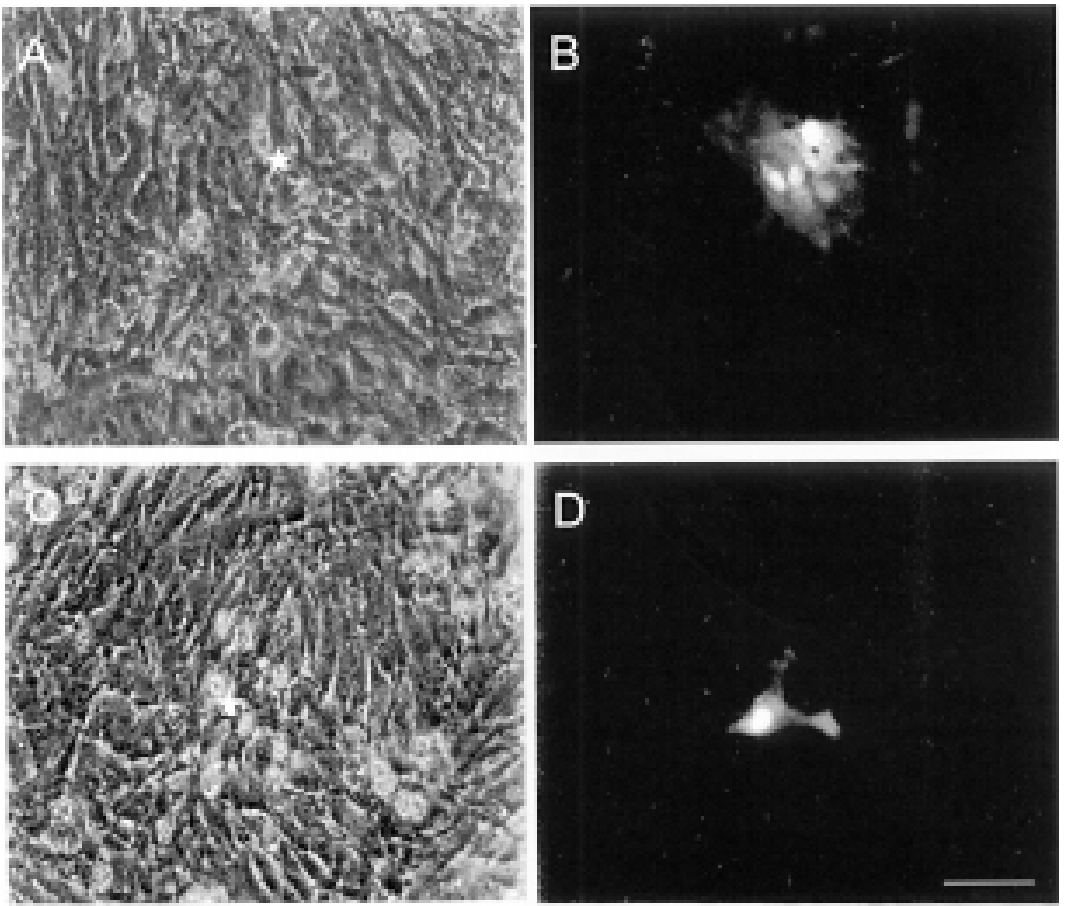

Figure 5 - Photomicrographs of primary cultures of neonatal mouse cardiomyocytes under phase contrast (left panels), and fluorescence (right panels). In the control culture (A and B), the dye spread to 4 cells adjacent to the injected cell. In the culture treated with serum that showed adrenergic-like effects on heart rate (in the isolated whole rabbit heart), the dye remained restricted to the injected cell (C and D). Calibration bar in D holds for all micrographs and indicates $50 \mu \mathrm{m}$.

Figure 6 - Histogram showing the extent of dye coupling in primary cultures of cardiomyocytes. The cultures were treated with sera from chronic chagasic (CCh) patients showing adrenergic-like effects ( $p a-$ tients 1 and 2) and from orthopedic patients, both compared to untreated cultures (control). The cells were injected with the fluorescent dye Lucifer yellow. The extent of coupling was divided into four classes: $0,1-3,4-6$ and $>6$ according to the number of

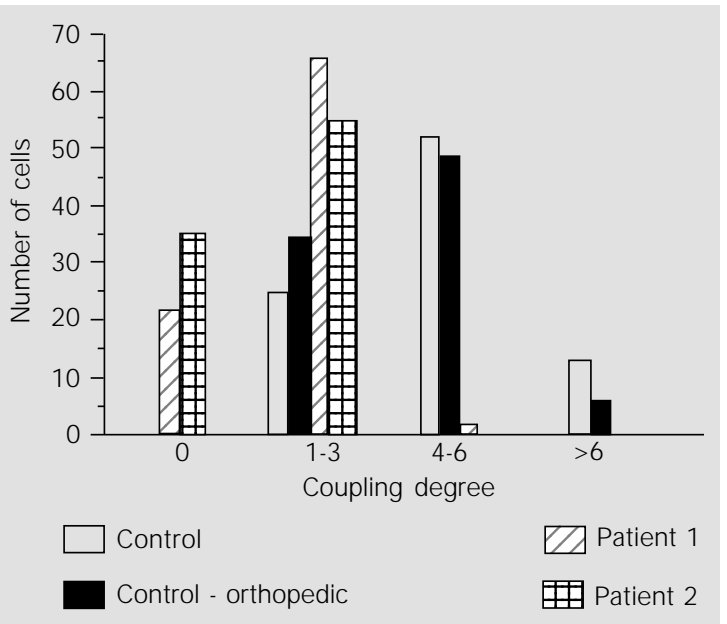
cells to which dye was

transferred upon injection into one cell. In control untreated cultures and in cultures treated with serum from the orthopedic patient, $73 \%$ and $65 \%$ of the injected cells were well coupled (coupling degree: $\geq 4$ cells), respectively. In cultures treated with sera from chagasic patients 1 and 2 , the percentage of dye-uncoupled cells was $22 \%$ and $35 \%$, respectively. Coupling was significantly decreased in cultures incubated with sera from both CCh patients $\left(\mathrm{P}<0.01, \chi^{2}\right)$.
Results from longitudinal studies evaluating clinical and electrocardiographic aspects in CCh patients show that the occurrence of conduction disturbances, specifically AVB, and complex arrhythmias are very often associated (12). Whether these disturbances are related to the muscariniclike activity of serum from $\mathrm{CCh}+$ patients needs to be further evaluated.

In another series of experiments we investigated the effect of sera from $\mathrm{CCh}$ patients exhibiting beta-adrenergic-like effects in the whole heart preparation on intercellular communication in primary cultures of murine embryo cardiac myocytes. Addition of the sera at the dilutions used for the whole heart $(1: 100 \mathrm{v} / \mathrm{v})$ did not induce major alterations in the cultures as evaluated by dye spread (data not shown). However, at 1:10 dilution sera from these patients strongly decreased coupling after $24 \mathrm{~h}$, as illustrated in Figure 5. Observe that while in the control untreated culture Lucifer yellow injected into one cell promptly spread to several other cells (Figure 5B), in the serum-treated culture the dye was restricted to the injected cell (Figure 5D). Figure 6 gives a quantitative view of the uncoupling induced by this $\mathrm{CCh}$ serum diluted 1:10 (v/v). Control untreated cultures (open bars) showed coupling degrees ranging from 1-3 cells to more than 6 cells coupled to the injected cell, with maximum frequency in 4-6 cells. Treatment with serum from a normal patient (black bars) for $24 \mathrm{~h}$ did not change this profile. In contrast, treatment with sera from two distinct $\mathrm{CCh}$ patients (hatched bars) with beta-adrenergic-like activity tended to uncouple the cells, displacing the maximum frequency towards 1-3 cells with virtual absence of coupling to 4 or more cells and a significant number of cells completely uncoupled (coupling degree 0 ). Figure 7 shows that, for the serum from CCh patient 1 , the uncoupling effect can only be detected after 24-h exposure. This implies that the observed effect is not acute, in contrast to what is seen in the 


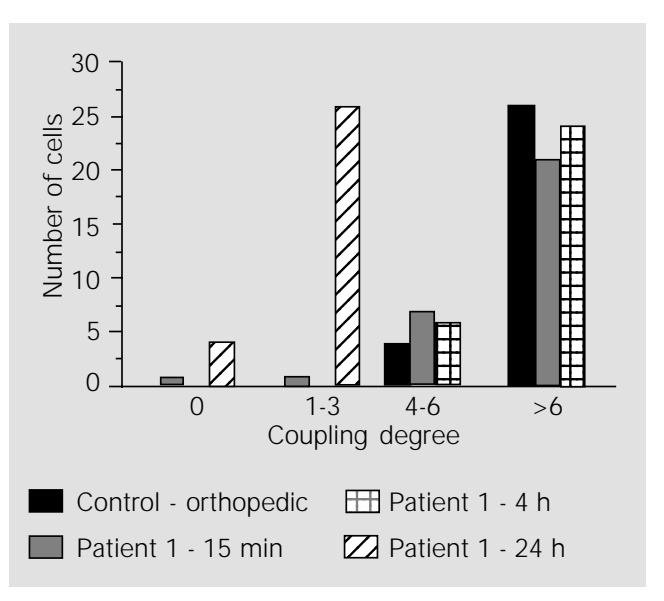

isolated hearts as described above. In fact, the expected result after activation of the cardiac beta-adrenergic receptor would be increased coupling as reported by De Mello (13) and Burt and Spray (14), resulting from protein kinase A (PKA) activation. Our observations, restricted to prolonged culture exposure to sera containing beta-adrenergiclike activity, may be explained in many different ways. It is known that receptor activation by these sera is not identical to the natural agonist activation. Indeed, there was no desensitization with most sera tested. Binding experiments (15) suggest that the agonist and the serum binding sites are diverse. Therefore, it is reasonable to assume that activation by sera may trigger intracellular cascades that are not those activated by the natural agonist, resulting in diverse effects. Alternatively, given that the serum effect does not desensitize the receptor, one
Figure 7 - Time dependence of the uncoupling effects of chagasic sera. Histogram showing the degree of dye coupling in primary cardiomyocyte cultures. The cardiomyocytes were incubated with serum from chagasic patient 1 for different periods of time. Control (black bars) is represented by cardiomyocytes incubated with an orthopedic patient's serum for $24 \mathrm{~h}$. Incubation with the chagasic patient's serum for periods of time varying from $15 \mathrm{~min}$ up to $4 \mathrm{~h}$ did not affect the dye coupling pattern observed in the control condition $\left(\mathrm{P}>0.01, \chi^{2}\right)$. However, $24 \mathrm{~h}$ after incubation with the chagasic senum coupling was significantly decreased in comparison to the control group $\left(\mathrm{P}<0.01, \chi^{2}\right)$.

may assume that PKA could be depleted after prolonged exposure to serum, resulting in the long-term decrease in junctional coupling. Increased coupling would not be seen during the shorter time exposures due to the fact that cultures were initially well coupled. These arguments, however, are highly speculative and it is clear that additional experiments are needed to identify the underlying mechanism.

\section{Acknowledgments}

The authors wish to acknowledge the valuable contributions of Cristina Borges e Sá and Paulo R. da Costa in collecting blood from the patients, Daisy Avanzi for excellent technical assistance, and Selma Farias de Oliveira, who participated in the early phase of the project.

\section{References}

1. Chagas C (1909). Nova trypanozomiase humana. Estudos sobre a morfologia e o ciclo evolutivo do Schizotrypanum cruzi n.gen., n.sp., agente etiológico de nova entidade mórbida do homem. Memórias do Instituto Oswaldo Cruz, 1: 59-65.

2. Farias de Oliveira $S$, Pedrosa RC, Nascimento J HM, Campos de Carvalho AC \& Masuda MO (1997). Sera from chronic chagasic patients with complex cardiac arrhythmias depress electrogenesis and conduction in isolated rabbit hearts. Circulation, 96: 2031-2037.

3. Masuda MO, Levin M, Oliveira SF, Costa PCS, Lopes Bergami P, Almeida NAS, Pedrosa RC, Ferrari I, Hoebeke J \& Campos de Carvalho AC (1998). Functionally active cardiac antibodies in chronic Chagas' disease are specifically blocked by Trypanosoma cruzi antigens. FASEB J ournal, 12: 1551-1558.

4. Sterin-Borda L, Fink S, Diez C, Cossio P \&
Debracco MME (1982). Beta-adrenergic effect of antibodies from chagasic patients and normal human lymphocytes on isolated rat atria. Clinical and Experimental Immunology, 50: 534-540.

5. Borda ES, Pascual J, Cossio P, Vega M, Arana R \& Sterin-Borda L (1984). A circulating IgG in Chagas' disease which binds to ß-adrenoreceptors of myocardium and modulates their activity. Clinical and Experimental Immunology, 57: 679-686. 
6. Meirelles MNL, Araújo-J orge TC, Miranda CF, Souza WE \& Barbosa H (1986). Interaction of Trypanosoma cruzi with heart muscle cells: ultrastructural and cytochemical analysis of endocytic vacuole formation and effect upon myogenesis. European J ournal of Cell Biology, 41: 198206.

7. Campos de Carvalho AC, Tanowitz HB, Wittner M, Dermitzel RR, Roy C, Hertzberg EL \& Spray DC (1992). Gap junction distribution is altered between cardiac myocytes infected with Trypanosoma cruzi. Circulation Research, 70: 733742.

8. Carrasco HA (1983). Diagnostico de dano miocardico en la enfermidad de Chagas. Textos de la Universidad de Los Andes. Consejo de Publicaciones de la Universidad de Los Andes, Merida.
9. Carrasco HA, Guerreiro L, Parada $H$, Molina C, Vega E \& Chuecos R (1990). Ventricular arrhythmias and left ventricular myocardial function in chronic chagasic patients. International J ournal of Cardiology, 28: 35-41.

10. Lown B \& Wolf M (1971). Approaches to sudden death from coronary heart disease. Circulation, 44: 130-142.

11. Elies R, Ferrari I, Wallukat G, Lebesgue D, Chiale P, Elizari M, Rosenbaum M, Hoebeke J \& Levin M (1996). Structural and functional analysis of the B cell epitopes recognized by anti-receptor autoantibodies in patients with Chagas' disease. J ournal of Immunology, 157: 4203-4211.

12. Maguire J H \& Hoff R (1987). Cardiac morbidity and mortality due to Chagas' disease: prospective electrocardiographic study of a Brazilian community. Circula- tion, 75: 1140-1145.

13. De Mello WC (1984). Effect of intracellular injection of CAMP on the electrical coupling of mammalian cardiac cells. Biochemical and Biophysical Research Communications, 119: 1001-1007.

14. Burt J M \& Spray DC (1988). Inotropic agents modulate gap junction conductance between cardiac myocytes. American J oumal of Physiology, 254: H1206$\mathrm{H} 1210$.

15. Quintero Hernandez CC, Diáz GLE, Pedrosa RC, Kurtenbach E, Masuda MO, Nascimento J HM \& Campos de Carvalho AC (1999). Interaction of chagasic antibodies with the allosteric site of atrial muscarinic acetylcholine receptors. Memórias do Instituto Oswaldo Cruz, 94 (Suppl II): 107 (Abstract). 